\title{
A Cognitive Research on Hand Metaphors in English
}

\author{
Ming Zhang \\ Zhejiang Yuexiu University, Shaoxing, China \\ Email:20131050@zyufl.edu.cn
}

How to cite this paper: Zhang, M. (2021) A Cognitive Research on Hand Metaphors in English. Open Access Library Journal, 8: e7436

https://doi.org/10.4236/oalib.1107436

Received: April 20, 2021

Accepted: May 23, 2021

Published: May 26, 2021

Copyright (c) 2021 by author(s) and Open Access Library Inc.

This work is licensed under the Creative Commons Attribution International License (CC BY 4.0).

http://creativecommons.org/licenses/by/4.0/

\begin{abstract}
In the past years, metaphor was mostly confined to literature and rhetoric as a figure of speech while resent metaphor study has a more extended scope. Especially over the past thirty years, cognitive linguists and their theories have brought much impact on the research of the relationship between metaphor and human thoughts: metaphor is a way of conceiving, our ordinary conceptual system, in terms of which we both think and act, is fundamentally metaphorical in nature. A large part of the way we speak in our daily life derives from the way we speak about our body-part terms. This paper collects Hand expressions in English for a purpose of understanding the working mechanism of body metaphors. This is also an elaborating try for the relationships among metaphor, body and language by means of self-examination and data support, all with great hopes to contribute to metaphor research and language acquisition.
\end{abstract}

\section{Subject Areas}

Linguistics

\section{Keywords}

Cognitive Research, Hand, Metaphor

\section{Introduction}

Body metaphor is formed by mapping other target domains based on the similarity with body organs in form, position and function. This mapping is based on the similarity of the two conceptual domains in form, function, and location to form the metaphor of the human body [1]. This paper is concerned with elaborating the relationships among metaphor, body and language by means of focusing on a cognitive study on hand metaphors in English. It is common know- 
ledge that words are often used in figurative sense, languages can be figurative. Most people are very apt at using figurative language almost unconsciously. Metaphor is very common in human languages. According to Richards [2], in every three sentences of any text, there is a metaphor. Language cannot be separated from metaphor, which is a basic feature of languages, and human beings cannot be separated from language as well as metaphor. Metaphor which exists in our daily life, is a cognitive tool for human beings to conceptualize abstract categories. In our daily communication, we are used to saying that 'foot of the mountain、 legs of the table、 head of department、face of a watch 、 eye of a needle、 mouth of a hole、 hands of a watch' and so on. A significant landmark in the cognitive paradigm studying of metaphor which challenged the traditional theory in a coherent and systematic way first appeared in Lakoff and Johnson's [3] ground-breaking book titled Metaphors we live by. In this book, the authors richly document that much of our understanding of everyday experience is structured in terms of metaphor. It is pervasive in everyday life, not just in language but in thought and action. Our ordinary conceptual system, in terms of which we both think and act, is fundamentally metaphorical in nature.

Metaphor is not only a linguistic phenomenon, but it is more importantly a way of thinking. In some cases metaphors are large-scale structures that influence our thinking about the whole areas of human experiences [4]. In our everyday life, metaphor is regarded as an important cognitive mechanism, owing to which we can understand and measure those unknown or unfamiliar objects and concepts in terms of those we known and familiar ones. The cognitive law that man cognize things from the near to the far, from entity to non-entity, from the simple to the complex, and from the concrete to the abstract determines the basic role of body parts in cognizing the world. And the metaphorization of body-part terms is one of the basic means of forming and expressing concepts [5].

\section{Research Method and Data Collection}

An effective method to fulfill the aim of this paper is to cooperate with the corpus linguistics which is a methodology rather than an independent branch of linguistics. Corpus-linguistic approaches allow rapid searches of patterns that can be investigated quantitatively and qualitatively [6]. This tool allows us for quick generation of frequency counts of selected items. Through large scale corpus linguistic studies, it is possible to make more general statements about broadly defined types. Based on this research method, I collected the data from the BNC (https://www.english-corpora.org/bnc/) online-service. As a result of simple search service of BNC (British National Corpus) online, there come up 33,175 matches having the word hand, including 2394 matches from spoken materials, 14208 matches from fiction, 1979 matches from magazine, 1984 matches from newspaper, 3424 matches from non-acad material, 5413 matches from MISC. Owing to the limited scale of the research, I chose parts of these representational matches of hand which are frequently used. 3. Literature Review 
The bud of metaphor started from the Plato period, growing throughout the history, with a continuously deepening process, and the focus of metaphor study changed several times and covered some of different developing stages with a lively generation features. There are metaphors in rhetoric study, metaphors in poetics study, metaphors in linguistics study and metaphors in philosophy study. Merely, these study models are not completely identical with every corresponding period simply, but serve as some certain gradual and coexistent continuum. Throughout the histories, it is possible to classify metaphors in a variety of ways. According to Zhang Pei's [7] works I could find one form founded on the synchronic principles with a great western feature. There are rhetorical metaphors including implicit metaphor, explicit metaphor, metonymy, synecdoche, allegory, conceit, personification, irony and so on; poetical metaphors including metaphor, imagery, allegory, symbol, myth, prototype and so on; linguistic metaphors including phonetic metaphor, lexical metaphor, syntactic metaphor and so on; philosophical metaphors including root metaphor, radical metaphor conceptual metaphor, similarity-creating metaphor and so on. I also could classify metaphors by diachronic principles and so we have newly-invented metaphor, dead metaphor and worn-out metaphor [8]. One more particular method divides metaphor into live metaphor, dying metaphor, dead metaphor, and fossilized metaphor [9]. Actually, the two varieties are preexistences of Max Black's terms of extinct metaphor, dormant metaphor and active metaphor [10]. Furthermore, the metaphor study in China has its unique style, and could be found in the classic aesthetics and poetics as well as in the study of ethical philosophy. Besides, it also represents a vividly cultural quality and native characters. Generally speaking, we could divide it into three stages which supply the main research domains and models of metaphor in Chinese: The time before Qin and Han dynasty in China is the first stage with a great stress on the study of cognitive philosophy; the time from Han and Wei dynasty to Tang and Song dynasty is the second stage which turns an emphasis on the poetics study; the last stage ranges from Song dynasty to the end of the Qing dynasty concentrating on the study of rhetoric. At the time after the new China's build till today, we have two more stages divided by the boundary of the $80^{\text {th }}$ age. Before that, the researchers paid most of their attentions on the study of the native resources and seldom considered the western situations. And then after that, the researchers started to stress on fetching in the western theories and proving them with the native resources.

Although the researches on metaphor in the West and the East both have a long history, the research scope and depth are very limited until recently the cognitive approach is imported into metaphor researches. In tracing the development from the traditional to a cognitive conception of metaphor, we now have arrived at a key point. Metaphors act as cognitive instruments. This means that metaphors are not just a stylistically attractive way of expressing ideas by means of language, but a way of thinking about things and actions. Based on a 
great development of the cognitive science, cognitive linguistics is an approach to language that is based on our experience of the world and the way we perceive and conceptualize it. It is today represented by three main approaches: the experiential view, the prominence view and the intentional view of language [11]. Cognitive linguistics provides us a new perspective and a new approach to language research. A famous Chinese researcher Wang Yin described in his book Cognitive Linguistics [12] that the term "cognitive linguistic" first appeared in 1971 , and originally meant the real discipline of researching the language system in the brain. But it is in fact different from what we broadly think of the cognitive linguistics today. Factually, cognitive linguistics established itself as a coherent, identifiable approach about two decades ago, marked by the first International Cognitive Linguistics Conference and by the publishing of the journal Cognitive Linguistics, which first appeared in 1990 [13]. By that time, the major theoretical foundations had been laid and a substantial amount of empirical data had already been gathered to support and develop those theories, and a steadily increasing number of scholars world-wide have taken up the challenge of mapping out the structure and dynamics of language in use from a cognitive perspective.

As some researchers hold their view that cognitive linguistics has not been formed as a complete theoretical system, so the scholars' understandings on it are anyone's guess for some times. No matter how scholars think it is an approach or a theory, cognitive linguistics is characterized by adherence to three central positions. First, it denies that there is an autonomous linguistic faculty in the mind; second, it understands grammar in terms of conceptualization; and third, it claims that knowledge of language arises out of language use [14]. Combining many famous cognitive linguists' researches on the basic contents, methods and views with his own understanding, Wang Yin [12] defined cognitive linguistics as a rising, cross subjects and unitive explanatory discipline to language by means of cognitive model (cognitive strategy) and knowledge structure. It is based on embodied philosophy, starting from human experiences and cognition, focusing on conceptual structure and meaning research, and seeks the cognitive model behind language facts. The cognitive strategy mainly includes interactive embodiment, image schema, prototype, categorization, conceptualization, cognitive model (including frame), construal, metaphor (including metonymy), conceptual blending and so on.

\section{Metaphorical Mappings of Hand in English}

In the modern cognitive linguistic view, metaphor is based on human being's own experience of knowing the world and the body-part terms are the first and closest objects directly experienced by human beings. As one of the most distinctive organs in human body, hand usually was used to understand lots of other conceptual domains. This accords with a sequence of rules by which human beings cognize and conceptualize the world. Human beings first know of some 
solid, corporeal and concrete objects around them, including their body parts. Then their cognizance comes into a further stage, and what human beings have been familiar with, including body organs, becomes the base on which they can cognize and conceptualize other things, especially the invisible, abstract and inenarrable things. Under these processes it formed metaphorical languages and cognitive conceptualizations.

\subsection{Mappings from Hand to Non-Body Domains}

\subsubsection{Mappings from Hand to Concrete Domains}

Lexical change in word meaning is very common in English, and it has a great impact on human beings' concept construction. But it seems that languages have a kind of inbuilt stability for core meanings which speakers could rely on for flexible extended uses. From a linguistic perspective, not from the philosophy perspective, the core meaning or prototype of hand should be human 'hand' (an organ attached to a forearm by the wrist), which is then extended to various other meanings and categories by means of metaphorization.

Every organ has its own biological function, and when various functions of hand are mapped onto another outside entity, the metaphorical uses of hand expressions appear. In English, a pioneering metaphorical use of hand is related to the concrete objects which are closely correlated with hand. For example those objects may be used by a hand, made by a hand, held by a hand, contacted with a hand, and so on. Object parts look like a hand or function like a hand, in the sense that hand-shaped objects and tools are used like human hands. Those concrete objects all have close relationships with hand. In the first original model, the hand maps to concrete objects directly based on the basic logical in human everyday experiences.

Additionally, we could examine mappings from body parts domains to concrete domains as another metaphorization phenomenon of lexicalization. There are lots of English examples which serve as an evidence for and a result of the metaphorical lexicalization. For example: handbag, handcraft, handbill, handiwork, hand truck, hand wash, handout, handball, hand mirror, hand-jack, hand arches, hand axes, hand calendar, hand gun. Besides, there are also many other ways of hand in lexicalization process. We can find out two similar ways from those examples in metaphorically lexicalized process of hand. One is the hand combined with another object or concept that contact with hand to form a fixed word group. The next is the hand combined with another object or concept to form one new word. Always the processes are viewed as meaning extensions or metaphorical entailments related to double-level or multi-level mappings among different domains. For example: handle, handler, handling, handleable, handleability.

To sum up, this mapping which is based on similarity in position, shape, and function between hand and other concrete objects belongs to those human beings' basic and lower cognitive activities. This is also a base for higher and further mappings, especially mapping to abstract domains. 


\subsubsection{Mappings from Hand to Abstract Domains}

The appearances of metaphors which are formed from hand mapping to concrete domains demonstrates the way human beings first cognize and conceptualize their surrounding world which belongs to a simple and almost single-level mapping model based on similarities and correlations. Although these kinds of mappings only belong to elementary cognitive activities, they play an important role in the basic cognitive type and process in which human beings define the world. Along with the deepening of cognitive and developmental needs, human beings construct their knowledge not only by single-level models but also by double-levels and multi-levels. In fact, people produce more abstract mappings which reflect a higher cognitive ability that is based on psychological and functional similarities between hand within various abstract domains.

Due to the basic logic of the multifunction of hand in our daily acts, the mappings onto abstract domains are easily performed. The direct reflection of this in language is that hand could be used as verbs to express the action concept. At the same time, the hand has another way of mapping onto abstract action domains by combining with certain active verbs together as fixed phrases, for example hand-drawn, hand woven. Although hand combines with nouns directly, they have implicit behavior action domains which belong to intervenient domains between concrete and abstract to some degree. In addition to above, there is another special metaphorization process in which body-parts domains map onto abstract domains, which is metonymy.

\subsection{Mappings from Non-Body Domains to Hand}

We think that human beings used mappings from body part domains to non-body part domains in order to form and express their new concepts encountered in our everyday life. They view surrounding objects as similar to their body based on some similarities; and they also could view varied abstract domains as their body parts. The reason is that human beings at the first time are more familiar with their bodies than other surroundings. This kind of metaphorically mappings is at the first stage of human beings' cognitive development. Then, non-body part domains also could map onto body part domains which is the second stage of human beings' cognition. A simple method for us to distinguish the mapping trace is to find out the target component in these mappings. And the target component always named the target domain is generally highlighted in meanings. The second stage is an evidence of human beings' cognition improvement and is based on people's daily experience. From examples of non-body part domains mapping onto hand, we could well understand parts of these mappings' working mechanism. There are mainly spatial domains, color domains, quantity domains, quality domains, emotion domains, and action domains, all of which could map to hand.

Cognitive linguists hold a point of view that spatial metaphors take on especially important meanings to human beings among all kinds of metaphors. 
Many abstract concepts could be understood in terms of spatial metaphors [15]. Our world is a three dimensional space. Our body itself is a three dimensional object as well. So our body belongs to this three dimensional space domain. Among all these three dimensional concepts the first important one is the container concept which is closely related to the whole space domain. At one time people think that the sky is round and the earth is square, so all of us live in an inverted pot. This may be the original source of container concepts. Later on some concrete tools, other objects, and even our body itself also show people container concepts. Not only the concrete sources but also the abstract sources of container concepts which mean people's dream outside the sky are available to human beings' cognition and language expression. A container has different features and states of up and down, right and left, front and back, inside and outside, center and edge, full or empty, etc. All these spatial concepts are well reflected in language expressions by means of preposition metaphors. To be detailed, it means that those spatial domains map onto our body domains metaphorically and form various language expressions, most of which are conventional metaphors with a preposition.

Furthermore, people often "open or close" their hand in doing certain activities with a "full or empty". From a cognitive perspective, all of these cognitions of hand metaphors belong to container domains which are based on mappings that come from human beings' concrete and abstract sources of container states in the everyday experiences. Usually mappings between spatial domain and our body domain interact with each other. That is because our cognition is always enhanced and developable by cognition and recognition measures. Here what I am going to declare about the spatial domains mapping onto body-part domains exactly is a general spatial domain mapping onto sub-spatial domains. Our body itself has a three dimensional space and belongs to the spatial domains.

\subsection{Mappings within Body Parts Domains}

Besides the above mentioned metaphorization of our body part terms, one more mapping model should be pointed out, that is called a mapping within two body part terms, for example "the back of the hand". It means that one body part is mapped to another body part which belongs to a secondary structure mapping of the metaphorization. In this case, every body part could be both a source domain and a target domain at the same time and interacts with each other. But in the mapping processes, one body part plays a more central role preferring to be the target domain, while the other one leaves to be a modifier to the target as the source domain. And sometimes the boundary between the source domain and the target domain is fuzzy.

\section{Conclusions}

In all periods of the world, there are a lot of rhetoricians, philosophers, linguists and psychologists have made great contributions to metaphor study in almost 
every field. Although embodiment is the base of cognitive metaphor research, it is difficult to imagine and investigate to the end how human beings think in a metaphorical way and how human beings understand non-literal meanings. Metaphor is so ordinary that we use it unconsciously and automatically. First, most of the data that have been used in this chapter are from the free search service of BNC on line. We got many metaphorical uses of hand expressions, people view hand as basic objects, sections, moving things, powers, mysterious strength, relationships, status, orientation and so on. I picked up some representative examples and had examined and classified them mainly into three different mapping models based on those basic conceptual metaphors (Figures 1-3).

Model 1

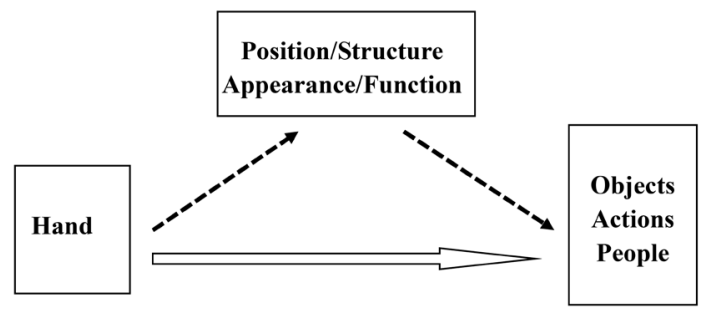

Figure 1. Mappings from hand onto non-body-part domains.

Model 2

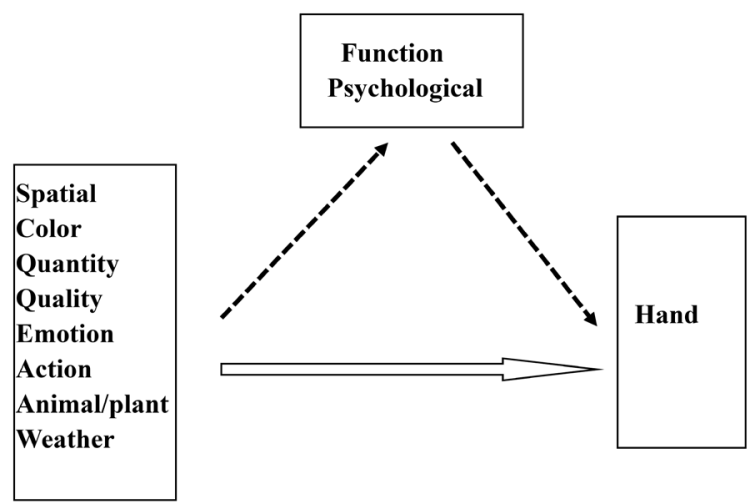

Figure 2. Mappings from non-body-part domains onto hand.

\section{Model 3}

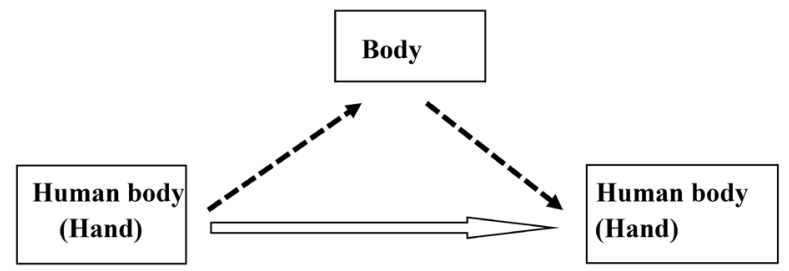

Figure 3. Mappings within two body parts.

From the data I found the fact that most of the expressions of English hand used in our daily life are metaphorical, although I did not do a very exact statistic 
percentage. This phenomenon partly validates the theory that metaphor is pervasive in everyday life, and our ordinary conceptual system, in terms of which we think and act, is fundamentally metaphorical in nature.

Second, from the data classification and explanation, I also could answer the research question: "How are the metaphorical expressions of hand motivated?" Both metaphor and metonymy are properties of concepts. In order to have a better understanding of certain concepts, people cognize hand related concepts by means of the metaphorization of the body part hand.

At last, metaphor is very common, and the language space of non-metaphor is very limited. Metaphor exists in all types of languages, but is not unique to literary languages. Metaphor can be seen in many fields such as science, technology, business, law, finance, art, architecture and so on. During this cognitive study of hand metaphors in English, those metaphors reveal the internal relationship between culture and body, but much remains to be explored and discovered. For example, what is the best way to identify and classify this kind of metaphors? In the metaphorization process, what kind of mapping exactly happened? What is a perfect data collection and storage? These problems also become the deficiencies of this paper due to the limitation of the author's time and research level. And further researches should also invoke more scientific and logical as well as more intensive and extensive classifications.

\section{Conflicts of Interest}

The author declares no conflicts of interest regarding the publication of this paper.

\section{References}

[1] Liu, S. (2020) A Review of Body Metaphors from the Cognitive Perspective. Young Literator, 36, 171-172.

[2] Richards, I.A. (1936) The Philosophy of Rhetoric. Oxford University Press, Oxford.

[3] Lakoff, G. and Johnson, M. (1980) Metaphors We Live by. University of Chicago Press, Chicago.

[4] Lee, D. (2001) Cognitive Linguistics: An Introduction. Melbourne, Oxford; Oxford University Press, New York.

[5] Lu, W. (2003) The Metaphorization of Body-Part Terms. Foreign Language Education, 24, 23-28.

[6] Krennmayr, T. (2015) What Corpus Linguistics Can Tell Us about Metaphor Use in Newspaper Texts? Journalism Studies, 16, 530-546. https://doi.org/10.1080/1461670X.2014.937155

[7] Zhang, P. (2004). The Life of Metaphors. Beijing University Press, Beijing.

[8] Lodge, D. (1972) 20th Century Literary Criticism: A Reader. Routledge, London. https://doi.org/10.4324/9781315837130

[9] Hartwell, P. and Bentley, R.H. (1982) Open to Language: A New College Rhetoric. Oxford University Press, New York.

[10] Ortony, A. (1993). Metaphor and Thought. Cambridge University Press, Cam- 
bridge. https://doi.org/10.1017/CBO9781139173865

[11] Williams, T.A. (2010) Task-Based Language Teaching: A Reader. ELT Journal, 64, 351-354. https://doi.org/10.1093/elt/ccq032

[12] Wang, Y. (2007) Cognitive Linguistics. Shanghai Foreign Language Education Press, Shanghai.

[13] Janssen, T.A.J.M. and Redeker, G. (1999) Cognitive Linguistics, Foundations, Scope, and Methodology. De Gruyter Mouton, Berlin. https://doi.org/10.1515/9783110803464

[14] Croft, W. and Cruse, D.A. (2004) Cognitive Linguistics. Cambridge University Press, Cambridge. https://doi.org/10.1017/CBO9780511803864

[15] Lan, C. (1999) A Cognitive Approach to Spatial Metaphors in Chinese. Foreign Language Teaching and Research, 43, 7-15. 